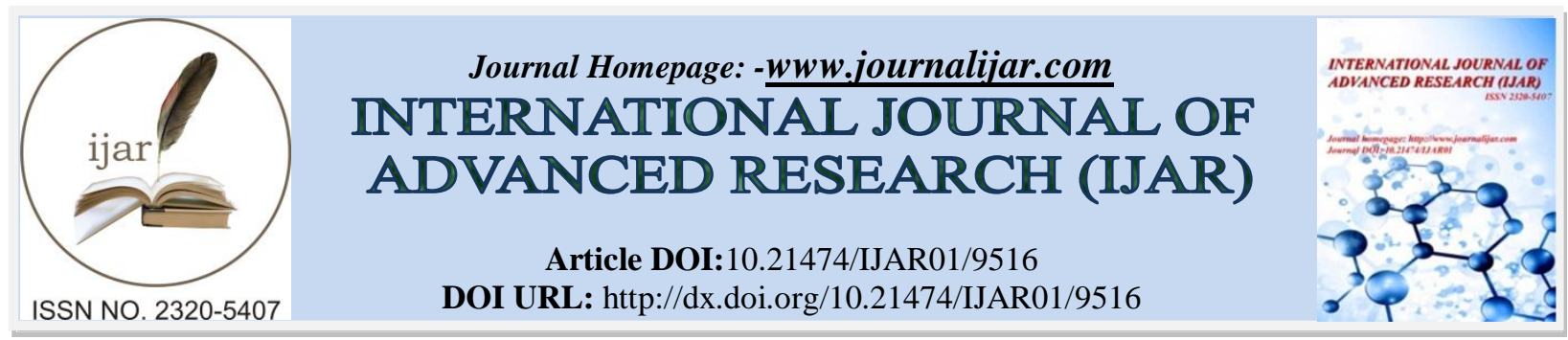

RESEARCH ARTICLE

\title{
DETECTION AND MOLECULAR CHARACTERIZATION OF ESBL PRODUCING E. COLI ISOLATED FROM POULTRY DROPPINGS AND ITS ENVIRON.
}

Andy I. E., Tiku, D. R., Okpo E. A., Mboto C. I. and Utsalo S. J.

Department of Microbiology, Faculty of Biological Sciences, University of Calabar, Nigeria.

\section{Manuscript Info}

Manuscript History

Received: 06 June 2019

Final Accepted: 08 July 2019

Published: August 2019

\begin{abstract}
Detection and molecular characterization of ESBL producing $E$. coli isolated from poultry droppings and its environ was investigated. Samples of poultry droppings (20), air (12), water (12) and soil (12) were collected from four randomly selected poultry farms within Calabar Municipal Local Government Area of Cross-River State. The samples were processed and E. coli isolates were identified using Standard Microbiological Techniques. ESBL phenotypic detection was carried out using Double Disc Synergism Test (DDST) while molecular detection of TEM, SHV and CTX-M genes in the E. coli isolates was carried out using Polymerase chain reaction (PCR). Results obtained revealed that 56 bacteria species were isolated from the samples, out of which $30(53.57 \%)$ were E. coli while $12(21.43 \%)$ were ESBL positive. A higher prevalence of ESBL producing E. coli was observed with samples of the poultry droppings $(30 \%)$ as compared to that recorded with the air (8.33\%), water (16.67\%) and soil (25\%) samples collected from the poultry farms. TEM, SHV, CTX-M, CTX-M-9 and CTX-M-15 genes were detected in $28.57 \%, 33.3 \%, 11.9 \%, 4.976 \%$ and $21.43 \%$ of the E. coli isolates while BLa OXA and CTX- M-2 genes were not present in the E. coli strains. However, the study has shown that ESBL producing E. coli circulate within poultry droppings and its environs. Hence, poultry farms are important source for ESBLproducing bacteria which causes difficult-to-treat infections in humans. Therefore, and integrated "one health" surveillance system becomes a necessity in monitoring transmission events and detection of resistant bacteria in a timely manner.
\end{abstract}

Copy Right, IJAR, 2019,. All rights reserved.

\section{Introduction:-}

External-spectrum beta-lactamase (ESBL) producing Enterobacteriaceae are increasing in prevalence worldwide (Hetty et al., 2019). ESBLs confer resistance to most beta-lactam antibiotics including third and fourth generation cephalosporin, which severely limits treatment possibilities for infections caused by these bacteria. Production of Extended- spectrum beta-lactamases (ESBLs) is the most common mechanism of resistance to third-generation cephalosporin among enterobacteriaceae including Klebsiella pneumonia and Escherichia coli (Paterson and Bonomo, 2005; Pitout and Laupland, 2008). ESBL determinants have been detected not only in clinical isolates but also in commensal bacteria from humans and animals and in isolates from products of the food chain and sewage,

Corresponding Author:-Andy I. E

Address:-Department of Microbiology, Faculty of Biological Sciences, University of Calabar, Nigeria. 
revealing distribution and suggesting the presence of environmental reservoirs for these resistance determinants (Brinas et al., 2003; Ewers et al., 2011).

The increase in antimicrobial-resistant bacteria of animal origin resembles the process in humans about two decades ago (Ogbulu et al., 2013). Since the late 1990s, extended spectrum beta-lactamases (ESBL) producing enterobacteriaceae in particular $E$. coli, have emerged globally. Initially, ESBL producing bacteria were only observed in human medical practice (Olowe et al., 2012), but recent observations of these bacteria, first in companion animals and increasingly in livestock has initiated monitoring studies focused on livestock (Smet et al., 2010). ESBL producing E. coli are now being found increasing in numbers in food food-production producing animals leading to the hypothesis that animals might become infection sources or even reservoirs contributing to the spread of these bacteria (Carattoli et al., 2009). Numerous reviews of extended-spectrum beta-lactamase (ESBL) involved in antibiotic resistance and in particular of Escherichia coli with ESBLs have been published recently (Chong et al, 2011; Woodford et al, 2011). However, the problem with ESBL producing E. coli in relation to poultry production have not been specifically addressed. Although, it is uncertain whether ESBL E. coli represent a direct threat to poultry production, Nevertheless, ESBL E. coli certainly represents a major problem to human clinical medicine.

\section{Materials and methods:-}

\section{Study site and sample collection}

The study was conducted in selected locations within Calabar Municipal Local Government Area of Cross River State. A total of four poultry farms with about 250-1000 birds (chickens) on each farm was visited. On each farm visits, 5 single faecal droppings and 3 samples of air, water and soil within the chicken housing were collected with $\mathrm{an} \mathrm{eswab}^{\mathrm{TM}}$ (Hain Life science, Nehren, Germany) and sterile universal containers. The samples were immediately transported to the laboratory for further analysis.

\section{ESBL detection and antibiotics susceptibility testing}

On arrival in the laboratory, each sample was inoculated on two selective MacConkey agar plates containing $1 \mathrm{mg} / \mathrm{l}$ ceftazidime and cefotaxime respectively. Plates were incubated at $37^{\circ} \mathrm{c}$ for $24-48 \mathrm{~h}$. All colonies with typical E. coli morphology were selected and confirmed biochemically by API 20E tests. For all E. coli, ESBL- production was confirmed by the combined disk test with cefotaxime and ceftazidime alone and in-combination with ceftriazone. Qualtiy control for each batch of cephalosporin-containing MacConkey agar plates was performed with E. coli ATCC 25922 and a bla CTX-M-15 Positive E. coli isolate.

\section{ESBL typing using polymerase chain reaction (PCR)}

The genes coding for the following beta lactamases (bla ${ }_{\text {TEM,, SHV, }}$ CTX, OXA, CT-2, CT-9, CT-15) were detected by PCR amplification of genomic DNA in the cell lysates. The oligonucleotide PCR primers specific for beta lactamase genes, melting temperature and PCR products length are listed on Table 1.The gel was viewed in a gel doc system (Biorad Co. Ltd, USA) after electrophoresis. Standard Kilobase ladder used to confirm band sizes is shown on Table 2 Cycling conditions for polymerase chain reaction (PCR) is shown on Table 2. A concentration of each reagent in a mixture was 100-500ng of total genomic DNA, $10 \mathrm{mM}$ tris $\mathrm{HCl}(\mathrm{pH} 8.3), 2 \mathrm{mM} \mathrm{MgCl}_{2}, 0.5 \mathrm{pM}$ of each primer pair (forward and reverse). Two Hundred and fifty micro molar of each deoxynucleoside and triphosphate and $1 \mu \mathrm{l}$ of Taq DNA Polymerase for all the genes, blaTEM, SHV, CTX, OXA, CTX-2, CTX-9, CTX-15. The PCR products were separated in a $1 \%$ gel stained with ethidium bromide. The gel was run in an electrophoresis chamber at a voltage of $80 \mathrm{~mA}$ for 2 hours. A standard 1KB DNA ladder was used to size the bands. The band sizes are as follows:

Table 1:-Primers guide used in the study

\begin{tabular}{|c|c|c|c|c|}
\hline Primers & Nucleotide Sequence & $\mathrm{Tm}$ & Product Length & Ref \\
\hline TEM & $\begin{array}{l}\text { ATGAGTATTCAACATTCCGTG } \\
\text { TTACCAATGCTTAATCAGTGAG }\end{array}$ & 55 & 840 & Gracia et al., 2008 \\
\hline SHV & $\begin{array}{l}\text { ATTTGTCGTTCTTTACTCGC } \\
\text { TTTATGGGCGTTACCTTTGACC }\end{array}$ & 55 & 1051 & Gracia et al., 2008 \\
\hline CTX-M & $\begin{array}{l}\text { TTTGCGATGTGCAGTACCATAA } \\
\text { CGATATCGTTGGTGGTGCCATA }\end{array}$ & 51 & 544 & $\begin{array}{l}\text { Eldestem et al., } \\
2003\end{array}$ \\
\hline OXA & $\begin{array}{l}\text { TTTTCTGTTTGGGTTTT } \\
\text { TTTCTTGGCTTTTGTGTCTTG }\end{array}$ & 52 & 427 & Park et al., 2006 \\
\hline
\end{tabular}




\begin{tabular}{|l|l|l|l|l|}
\hline CTX-2 & $\begin{array}{l}\text { AAATGTGCTGGCTCCTTTCGTGAGC } \\
\text { AGGGTTCGTTGCAAGACAAGACTG }\end{array}$ & 60 & 1122 & Gracia et al., 2008 \\
\hline CTX-9 & $\begin{array}{l}\text { GTGACAAAGAGAGTGCAACGC } \\
\text { TAGATTCTCGCCCTAAGGCC }\end{array}$ & 60 & 856 & Sabata et al., 2000 \\
\hline CTX-15 & $\begin{array}{l}\text { CACACGTGGAATTTAGGGACT } \\
\text { GCCGTCTAAGGCGATAAACA }\end{array}$ & 55 & 996 & $\begin{array}{l}\text { Muzaheed et al., } \\
2008\end{array}$ \\
\hline
\end{tabular}

(Source: Sidjabat et al., 2009)

Table 2:-Standard band sizes used to confirm enzyme bands in PCR

\begin{tabular}{|c|c|c|}
\hline \multicolumn{2}{|l|}{ Kilo base } & Base Pairs \\
\hline- & 10 & $(10,000)$ \\
\hline 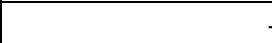 & 8 & $(8,000)$ \\
\hline 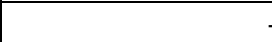 & 6 & $(6,000)$ \\
\hline . & 5 & $(5,000)$ \\
\hline 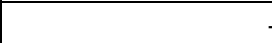 & 4 & $(4,000)$ \\
\hline 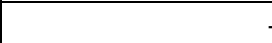 & 3 & $(3,000)$ \\
\hline . & 2 & $(2,000)$ \\
\hline . & 1.5 & $(1,500)$ \\
\hline 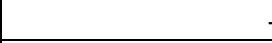 & 1.0 & $(1,000)$ \\
\hline . & 0.5 & $(500)$ \\
\hline
\end{tabular}

Table 3:-Steps of PCR process

\begin{tabular}{|c|l|}
\hline Step & \multicolumn{1}{|c|}{ Procedure involved } \\
\hline 1. & Initial denaturation at $95^{\circ} \mathrm{C}$ for 4 minutes \\
\hline 2. & Denaturation at $95^{\circ} \mathrm{C}$ for 30 seconds \\
\hline 3. & Primer annealing at $55^{\circ} \mathrm{C}$ for 30 seconds \\
\hline 4. & Primer extension at $72^{\circ} \mathrm{C}$ for 1 minute \\
\hline 5. & Final extension at $72^{\circ} \mathrm{C}$ for 10 minutes \\
\hline 6. & Holding temperature $4^{\circ} \mathrm{C}$ forever \\
\hline
\end{tabular}

\section{Polymerase chain reaction $(\mathrm{PCR})$}

This process was used to amplify and produce more genes. The Process involves three (3) major steps:

1. Denaturation

2. Annealing

3. Elongation

All of these steps take place in the PCR machine referred to as thermos-cyclers. Denaturation, this involves heating to about $90^{\circ} \mathrm{C}-95^{\circ} \mathrm{C}$, while annealing takes place at a lower temperature of about $70^{\circ} \mathrm{C}$. The elongation step is made possible by the enzyme Taq DNA polymerase derived from the organism Thermus aquaticus. This enzyme attaches the dNTPs and the primers to the separated stands of the DNA at specific points which carry the target gene. In the PCR process, extreme care was taken to avoid contamination. All processes were carried out in a sterile hood or room free from nucleases to avoid waste of very expensive reagents.

\section{Preparation of agarose gel}

The agarose gel was used for electrophoresis after polymerase chain reaction. To prepare a $1 \%$ gel, $1 \mathrm{~g}$ of agarose powder was weighed into $100 \mathrm{ml}$ of Tris-borate EDTA (TBE). This was placed in a microwave oven to melt and mix properly. Care was taken to ensure that the contents do not evaporate due to over-heating. It was allowed to cool to about $50^{\circ} \mathrm{C}$. Ethidium bromide was then added. The importance of this step was to allow for visibility of the amplicon bands under ultraviolet light. The mixture was allowed to cool further and then poured into gel tray with appropriate gel combs. The combs were used to create wells in the agarose gel where the PCR products will travel during electrophoresis. The gels were left to solidify (set) after which combs were removed.

\section{Gel electrophoresis}

The PCR products were introduced into the gel. They were then placed in the electrophoretic tank to separate the bands. DNA is negatively charged thus movement is from the negative to the positive end of the electrophoretic 
chambers. The electrophoresis step lasted 1 hour 30 mins to 2 hours. All PCR processes were carried out in bowls containing ice cubes $t$ prevent the development of primer dimers.

\section{Results:-}

\section{ESBL producers from samples}

Table 4 present the result of ESBL producers isolated from poultry droppings and it environ. it showed that 56 isolates from the samples were investigated for ESBL production. Of these, $30(53.57 \%)$ were $E$. coli and $12(21.43 \%)$ were positive for ESBL production. The result of the percentage prevalence of ESBL producing E. coli isolated from the samples is presented in Table 5. It showed that 6(30\%) of the 20 poultry dropping samples analyzed were positive for ESBL production, while 1(8.33\%), 2(16.67\%) and 3(25\%) were positive for ESBL production as observed with the air, water and soil samples collected from each of the farms visited.

\section{Results of ESBL typing using PCR}

The results of the genotype typing of the ESBL producing E. coli isolates are presented in Fig. 1, 2 and 3. Figure 1 present the result of PCR for 12 Isolates of E. coli strains. Isolate A, N, R and T had bands in TEM and SHV, M had bands SHV, CTX-15. S had weak bands in TEM and SHV but two strong bands in CTX-15, U had weak bands in SHV and CTX. Isolates J, K, O, Q and V had no bands. Figure 2 present the results for the PCR test of the second set of E. coli isolates. Isolates $A_{5}, A_{6}, A_{8}$, had bonds in TEM, $X$ had bonds in SHV and CTX-15, $A_{11}$ and $A_{12}$ had bands in CTX-15 and SHV respectively. Isolates $\mathrm{A}_{7}, \mathrm{~A}_{13}, \mathrm{~A}_{14}$ had no bands. Figure 3 present the PCR results of the phenotypically negative strains. It revealed that Isolates B had CTX-M, CTX-M-15, G had amplification in TEM and a weak band in CTX-M-9, H had CTX-M-15, P had TEM, SHV. Only Isolate C, D and I had no bands.

The summary of the bla genes recovered in this study is presented in Figure 4. A total of $12(28.57 \%)$ TEM; 14 (33.33\%, SHV; 5 (11.90\%) CTX-M; 2 (4.76\%) CTX-M-9 and 9 (21.43\%) CTX-M-15 were obtained. Bla OXA and CTX-M-2 were not found among the E. coli strains. 11 strains had no amplification with the primer sets used in this study

Table 4:-ESBL producers isolated from fecal droppings of poultry and its environ (air, water and soil)

\begin{tabular}{|l|c|c|c|}
\hline \multicolumn{1}{|c|}{ Sample } & Number of Isolates & $\begin{array}{l}\text { Number of E. coli } \\
\text { Isolated }\end{array}$ & $\begin{array}{l}\text { Number of ESBI } \\
\text { Positives (\%) }\end{array}$
\end{tabular}

Table 5: Prevalence of ESBL producing $E$. coli in the samples

\begin{tabular}{|l|l|l|}
\hline Environmental Samples & $\begin{array}{l}\text { Number of ESBL positive E. coli } \\
\text { isolates }\end{array}$ & \% prevalence \\
\hline Poultry Fecal droppings $(\mathrm{n}=20)$ & 6 & 30 \\
\hline Air $(\mathrm{n}=12)$ & 1 & 8.33 \\
\hline Water $(\mathrm{n}=12)$ & 2 & 16.67 \\
\hline Soil $(\mathrm{n}=12)$ & 3 & 25 \\
& 12 & 80 \\
\hline
\end{tabular}




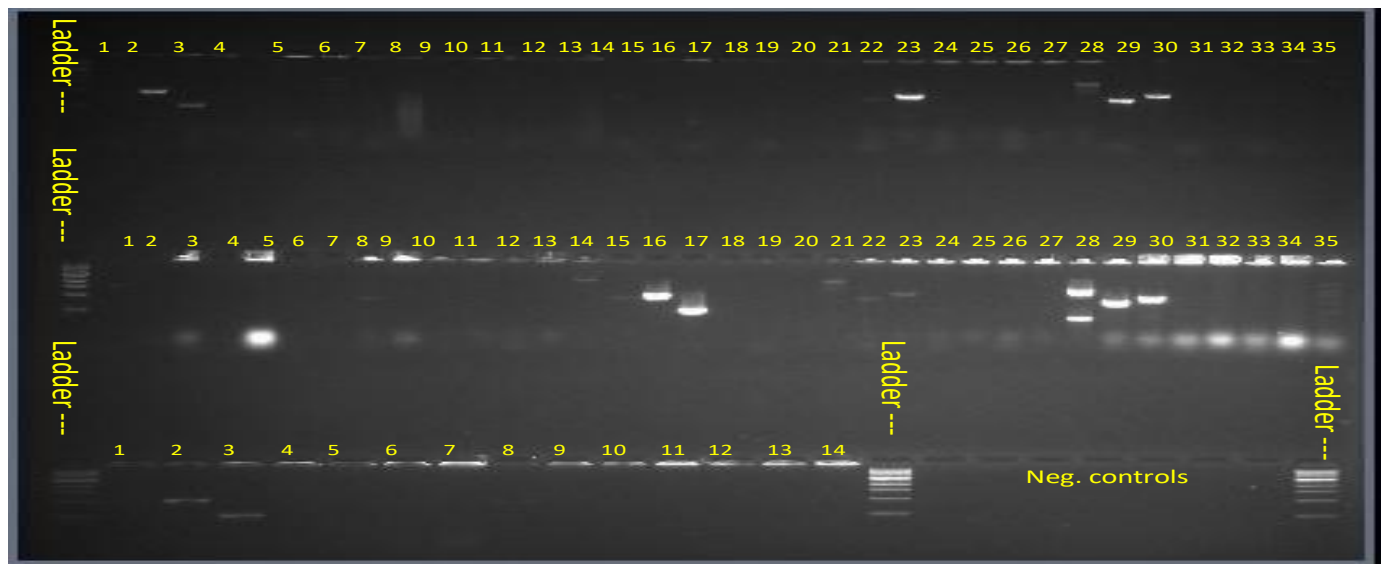

Fig 1:

ESBL typing for $12 \mathrm{E}$. coli isolates (A-U) using primers: TEM = Lane 1, SHV = Lane 2, CTX-M = Lane 3, OXA = Lane 4, CTX-M2 = Lane 5, CTX-M9 = Lane 6 and CTXM15 = Lane 7

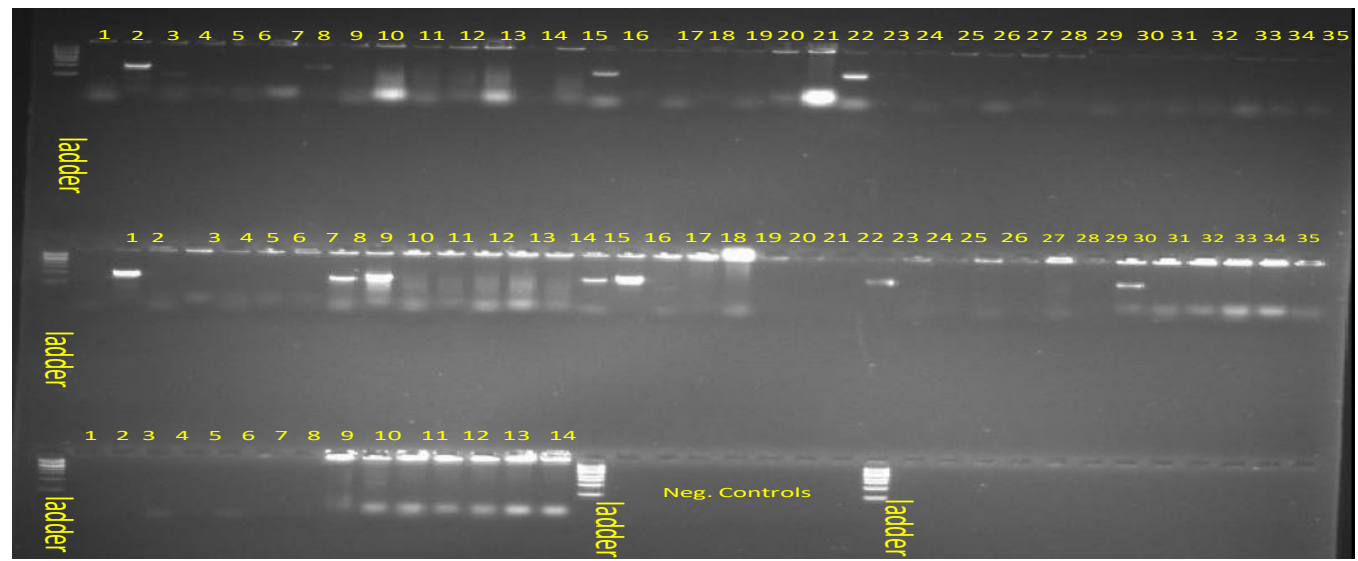

Fig 2: $\quad$ ESBL typing for $12 E$. coli isolates $\left(X-A_{14}\right)$ using primers:

TLM = Lane 1, SHV $=$ Lane $2, \mathrm{CT} X-\mathrm{M}=$ Lane 3 , OXA $=$ Lane 4

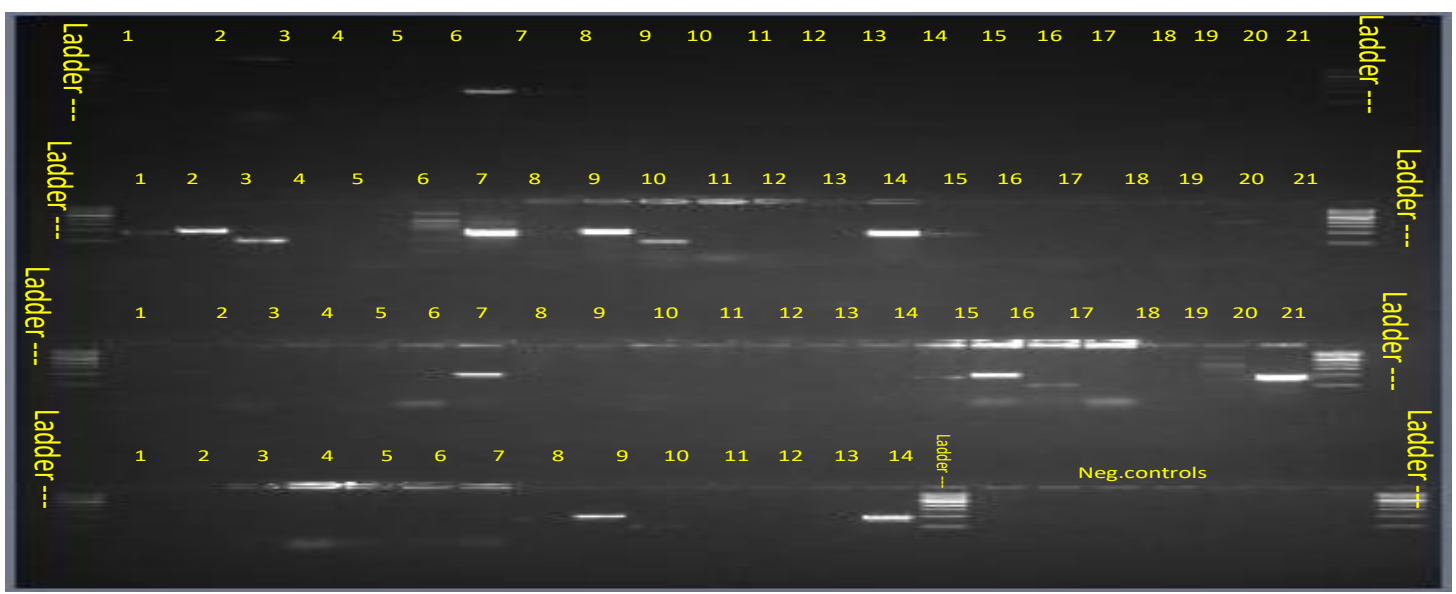

Fig 3: ESBL typing for phenotypically negative isolates using primers: TEM $=$ Lane 1, SHV Lane 2, CTX-M = Lane 3, OXA = Lane 4, TX-M2= Lane 5, CTX-M9= Lane 6 and CTX-M15 = Lane 7 


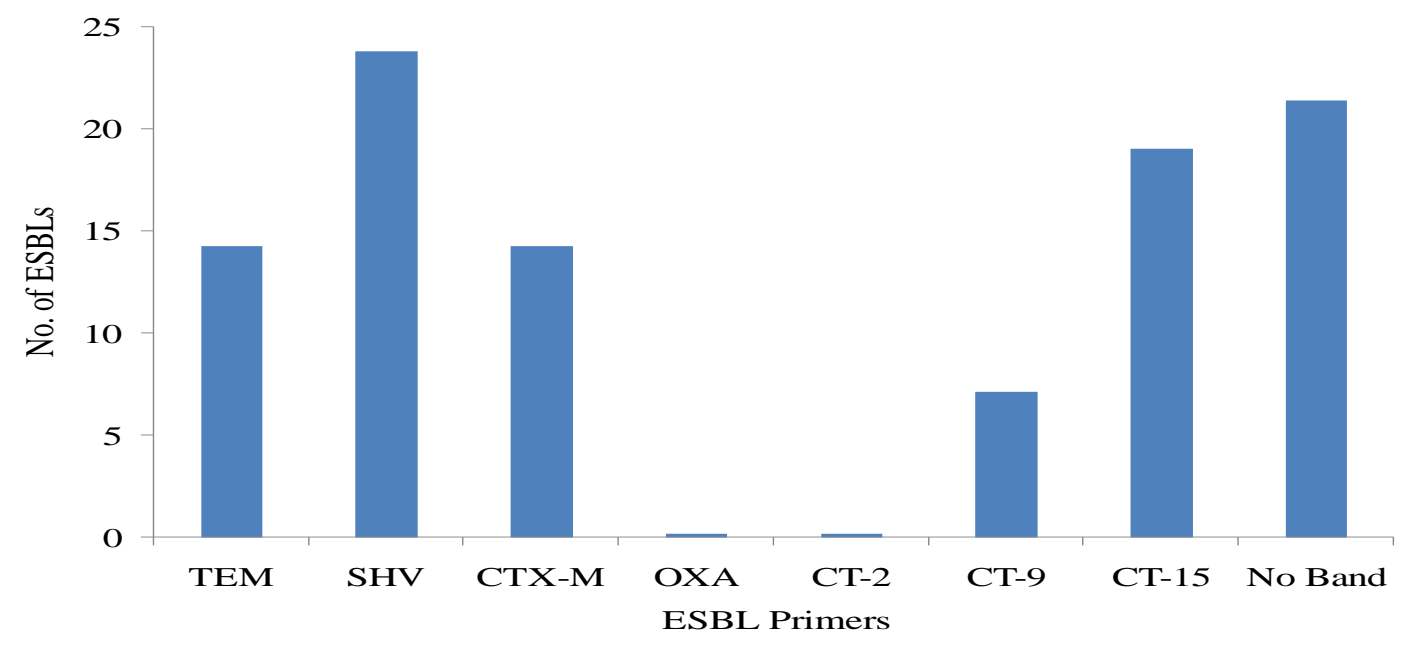

Fig 4: Bla genes recovered from study states

\section{Discussion:-}

Antibiotic resistance has continued to constitute serious problems not only in human medicine but also in animal husbandry, livestock management and vertinary medicine (Garrec et al., 2011; Ajayi et al., 2011). In this study, several methods of ESBLs detection were employed. Among 56 bacteria isolates from poultry droppings and its environ (air, water and soil), $30(53.57 \%)$ were identified as E.coli while $12(21.43 \%)$ were E5BL positive. This observation reiterates the finding in other studies that have reported antibiotic resistance among bacteria especially E. coli isolated from poultry, cattle and other animals at an alarming rate (Aibinu-et al., 2004; kozak et al., 2009; Ogunleye et al., 2009).

Extended- spectrum beta-lactamase indeed is a superbug of trouble to clinicians and microbiologist and is creating environmental stress to pharmaceutical pipeline in the development of new antibiotics. ESBL-producing E. coli are considered a major risk factor in human medicine, since infections with these bacteria are resistant to treatments with penicillin and cephalosporin. To reduce the risk, community originating ESBL $E$. coli either has to eliminated from poultry production or the occurrence has to be reduced to levels without risk to humans. Surveillance at farm level in this study clearly demonstrated a higher percentage prevalence (30\%) of ESBL producing E. coli in poultry droppings as compared to that observed with air (8.33\%), water (16.67\%) and soil (25\%) samples from the poultry farm environ. This observation was not surprising as similar study by Rikke et al., (2014) reported to have isolated ESBL producing Escherichia coli from poultry farms in Denmark. The prevalence of ESBL producing E. coli in poultry droppings as well as in barn environment (air, dust) was reported by Hetty et al (2015). Also Dierikx et al., (2013) reported that in the outdoor farm environment, ESBL- producing E.coli were frequently detected in soil and surface water. They further reported that other farm animals present in the poultry farm were also carriers of ESBLproducing E. coli. Overall the prevalence of the ESBL producing E. coli in the poultry environs (air, water and soil) could have visibily be influenced by the poultry droppings. Indeed, ESBL-producing E. coli have been frequently identified worldwide in the chicken production chain including reports from Nigeria and Tanzania (Ojo et al., 2016, Linda et al., 2019; Seni et al., 2016). Interestingly, studies from Netherland, Sweeden and Vietnam detected ESBLproducing ST-10 E. coli not only in chickens but also in high numbers in the poultry environ (Huijbers et al., 2014; Ueda et al., 2015; Van Hoek et al., 2015; Borjesson et al., 2016). The PCR experiment is designed to detect ESBLproducers genotypically. Following the screening of the E. coli isolates for ESBL genes using polymerase chain reaction (PCR), 12 (28.57\%) of blaTEM was recovered, while 14(33.33\%), 5(11.90\%), 2(4.76\%) and 9(21.43\%) of bla SHV, bla CTX-M, bla CTX-M-9, and blaCTX-M-15 were recovered respectively. Most amplification was observed with CTX-M. these findings suggest that blaCTX-M was more common among the ESBL genes in the E. coli isolates and this conforms to other studies by Olugbenga et al., (2015) and Hetty et al., (2019) . In this study, 
the high prevalence of EBSL production among the E. coli isolates is alarming and worrisome, as ESBL have been reported to be plasmid encoded implying that these resistance determinants are found in our environment and can be transferred from one organization to another. However, the prevalence of these E. coli isolates with ESBL production potentials further buttresses the hypothesis that animals might become inspection source or even reservoirs (the natural persistent source of inspection) contributing to the spread of these bacteria.

\section{Conclusion:-}

The study has shown that ESBL - producing E. coli circulate within poultry droppings and its environ. Hence poultry farms are important source for ESBL - producing bacteria which causes difficult-to-treat infections in humans. Despite wide spread agreement that integration of human and animal data is desirable for antimicrobial resistance surveillance there is very little, if any, integration of data in most low and middle - income countries like Nigeria. Therefore, an integrated "One Health "surveillance system becomes a necessity, so as to monitor transmission events and detect resistance bacteria in a timely manner.

\section{References:-}

1. Aibinu, E., Aednipekun, I, \& Odugbemi, T. (2004). Emergence of quinolone resistance among Escherichia coli strains isolated from clinical infections in some Lagos State hospitals in Nigeria. Nigerian Journal of Health and Biomedical Sciences, 3(2), 73-78

2. Ajayi, A., Oluyege, A., Olowe, O., \& Famurewa, O. (2011). Antibiotic resistance among commensal Escherichia coli isolated from faeces of cattle in Ado-Ekiti, Nigeria. Journal of Animal and Veterinary advances 10(2), 174-179

3. Brinas, L., Moreno, U., \& Zarazaga, A. (2003). Detection of CMY-2, CTX-M-14, and SHV-12 B lactamases in Escherichia coli fecal-sample isolates from healthy chickens. Antimicrobial Agents and Chemotherapy 47(6) 2050-2058

4. Carratoli, A. (2009). Resistance Plasmid farmilies in Enterobacteriaceae. Antimicrobial Agents and Chemotherapy, 53, 2227-2238

5. Chong, Y., Ito, Y., \& Kamimura, T. (2011). Genetic evolution and clinical impact in extended-spectrum BLactamase-producing Escherichia coli and Klebsiella pneumonia. Infection Genetics and Evolution, 11, 14991504

6. Direikx, C., Vander Groot, J., \& Smith, H. (2013). Extended-spectrum-beta-lactamase and AMPC-beta lactamase producing Escherichia coli in Dutch broilers and broiler farm. Journal of Antimicrobial Chemotherapy, 68, 60-67

7. Edelstem, M., Pimkin, M., Palagin, I., \& Stratchounski, L. (2003) Prevalence and Molecular epidemiology of CTX-extended spectrum beta-lactamases producing Escherichia coli and Klebsiella pneumonia in Russian hospitals. Antimicrobial Agents and Chemotherapy, 47, 3724-3732

8. Elvers, M., Grobbel, A., Bethe, H., Wieler, L., \& Guenther, S. (2001). Extended Spectrum beta-lactamases producing gram negative bacteria in companion animals action is clearly warranted. Antimicrobial Agents and Chemotherapy, 124, 10-17

9. Garrec, H., Drieux-Rouzet, L., \& Robert, J. (2011). Comparison of nine phenotypic methods for detection of extended spectrum beta-lactamase production by Enterobacteriaceae. Journal of Clinical Microbiology, 49(3), $1048-1057$

10. Gracia, Y., Szabo, D., Adams M., \& Paterson, L. (2008). Multi clonal outbreak of Klebsiella pneumonia producing extended spectrum beta lactamase CTX-M-2 and novel variant CTX-M-59 in a neonatal intensive care unit in Brazil. Antimicrobial Agents and Chemotherapy, 52, 1790-1793.

11. Hetty, B, Angela, M., Van Hoek, M., \& Franciska, S. (2015) Distribution, numbers and diversity of ESBLproducing E. coli in the poultry farm environment. Plos One, 10, 1-23

12. Hetty, B., Radiajo, A. HamidJaja, A., \& Schets, F. (2019). Detection of Extended - Spectrum Beta-Lactamase (ESBL)-producing Escherichia coli on flies at poultry forms. Applied and Environmental Microbiology 80(1) 239-246

13. Huijbers, M., Grant, A., \& Mevis, J. (2014). Extended-Spectrum and AMP C-Lactamase-producing Escherichia coli in broilers and people living and/or working on broiler farms. Prevalence, risk factors and molecular characteristics. Journal of Antimicrobial Chemotherapy 69, 2669-2675

14. Kozak, K., Boerlin, P., Janecko, R, \& Jardine, C. (2009) Antimicrobial resistance in Escherichia coli isolates from swine and wild small mammals in the proximity of swine farms and in natural environments in Ontario, Canada. Applied and Environmental Microbiology, 75 (3), 55 9-566 
15. Linda, F., Can, I., Kwabena, O., Charity, A., \& Jurgen, M. (2019). Detection and Characterization of ESBL producing Escherichia coli from Humans and Poultry in Ghana. Frontiers in Microbiology 9, (8):56-64

16. Smet, F., Nieurwer, T., \& Vandekereklove, M. (2010). Complete nucleotide sequence of CTX-M-5 plasmids from clinical Escherichia coli Isolates. Insertional events of transposons and insertion sequences, Plos One, $5(6), 578-592$

17. Muzaheed, Y., Dul, M, Adams A., \& Paterson, L. (2008) High prevalence of CTX-M-15 producing Klebsiella pneumonia among in patients with urinary tract infection in Southern India. Journal of Antimicrobial Chemotherapy, 61(6), 1393-1394

18. OLowe, O., Oladipo, D., Makanjuola, A., \& Olaitom, O. (2012). Prevalence of extended spectrum betalactamases carrying genes in Klebsiella $s p$ from clinical samples at Ile-Ife, South-Western, Nigeria International Journal of Pharma-Biosciences, 1(2) 201-212

19. Ogbolu, D., Alli, O., Olanipekun, I., \& Makinde, O. (2013). Faecal carriage of Extended spectrum beta- lacta mase (ESBL) producing commensal Klebsiella pneumonia and Escherichia coli from hospital out-patients in Southern Nigeria. International Journal of Medicine and Medical Sciences, 5(3), 97-105)

20. Ogunleye, A., Oyekunle, M., \& Sonibare, O. (2009). Multi drug resistant Escherichia coli isolates of poultry origin in Abeokuta, Southern western Nigeria. Veterinary Archives, 78(6), 501-509

21. Ojo, E., Schwartz, S. \& Michael, B. (2016). Detection and characterization of extended-spectrum betalactamase producing Escherichia coli from Chicken production chains in Nigeria. Vertinary Microbiology, $194,62-68$

22. Olugbenga, O., Olufumilayo, A., \& Olusalobim A. (2015). Phenotypic and molecular characterization of Extended-spectrum beta-lactamase producing Escherichia coli obtained from animal fecal samples in AdoEkiti, Nigeria. Journal of Environmental and Public Health, 35,1-7

23. Park, H. Robiesek, A., Jacoby, A, Sahm, D., \& Hooper, C. (2006) Prevalence in the United States of aac (6')1b-cr encoding a ciprofloxacin modifying enzyme. Antimicrobial Agents and Chemotherapy, 50, 395 3-39 55

24. Paterson, I., \& Bonomo, R. (2005) Extended Spectrum P-Lactamases: a clinical update. Clinical Microbiology Reviews, 18(4), 657-686

25. Pitout, D, \& Laupland, K. (2008) External spectrum beta-lactamase producing Enterobacteriaceae: an emerging public health concern. The Lancet Infectious Diseases 8(3), 159-166

26. Rikke, H., Olsen, B., Brice, R, \& Henrick, C. (2014) Extended Spectrum beta-lactamase producing Escherichia coli isolated from poultry; a review of current problems, illustrated with some Laboratory findings. Avian Pathology, 56, 37-43

27. Sabata, R., Tarrago, F., Navarro, E., \& Prats, G. (2000) Cloning and sequence of the gene encoding a novel cefotaxime-hycdrolyzing B-Lactamse (CTX-M-9) from Escherichia coli in Spain. Antimicrobial Agents and Chemotherapy, 44, 1970-1973

28. Seni, J., Falgenhauer, L., \& Matee, M (2016). Multiple ESBL producing Escherichia Coli sequence types carrying quinolone and aminoglycoside resistance genes circulating in companion and domestic farm animals in Mwanza, Tanzania, harbor commonly occurring plasmids. Frontiers in Microbiology, 7, 142-149

29. Sidjabat, E., Paterson, L., \& Doi, Y. (2009). Molecular epidemiology of CTX-M producing E. coli isolates at a tertiary care medical centre in Western Pennsylvania. International Journal of Antimicrobial agents 53(2),47334739

30. Ueda, S, Ngan, B., \& Yamamoto, Y. (2015). Limited transmission of bla (CTX-M-9)-type-positive Escherichia coli between humans and poultry in Vietnam. Antimicrobial Agents Chemotherapy, 59, 3574-3577

31. Van Hoek, H., Schouls, L., \& Van Duijkeren, E. (2015). Molecular Characteristics of extended -spectrum cephalosporin-resistant enterobacteriaceae from humans in the community. Plos One, 10

32. Woodford, N., Fagan, J., \& Ellington, J. (2006). Multiplex PCR for rapid detection of genes encoding CTX-M extended-spectrum beta-lactaamases. Journal of Antimicrobial Chemotherapy, 57, 154-155. 